\title{
The Impact of Shadow Education in Hong Kong: The Relationship between Private Tutoring and Hong Kong Secondary Students' English Academic Achievement
}

Cheng Ching Ho, Richard

Hong Kong Adventist College

\begin{abstract}
It is becoming more common for students to take extra lesson after school, and there are survey carried out by scholars which indicated that more than $70 \%$ of secondary school students need to take private tutoring classes after school in their final year of secondary school (Bray, 2013). This further indicates that shadow education has become a trend in Hong Kong. There are different types of private tutoring classes in Hong Kong, such as 1-on-1 tutoring or a group of 5 to 8 students' tutorial classes. Those classes are aimed to help students to perform better in public examination, but it has become more competitive in recent years. Even if you have satisfactory results at school, you may need to take extra classes too, since it has become a trend in the society. However, do students really need to take so many classes after school? Is the quantity of private tutoring lessons related to good academic results? In this study, I would like to find out the relationship between shadow education and students' academic achievements, and the elements that may affect the quality of shadow education.
\end{abstract}

Keywords: Curriculum, Education, Private tutoring, Qualitative research, Teaching 